\title{
Assessing the measurement invariance of the 10-item Centre for Epidemiological Studies Depression Scale and Beck Anxiety Inventory questionnaires across people living with HIV/AIDS and healthy people
}

\author{
Zahra Bagheri ${ }^{1}$, Pegah Noorshargh ${ }^{1}$, Zahra Shahsavar $^{2}$ and Peyman Jafari ${ }^{1 *}$ (])
}

\begin{abstract}
Background: Recently, extensive research has been reported the higher rate of depression and anxiety among people living with HIV/AIDS (PLWHAs) as compared to the general population. However, no single study has been carried out to investigate whether this disparity is a real difference or it happens due to lack of measurement invariance. This study aims to assess the measurement invariance of the Beck Anxiety Inventory (BAI) and 10-item Centre for Epidemiological Studies Depression Scale (CESD-10) questionnaires across PLWHAs and healthy individuals.

Methods: One hundred and fifty PLWHAs and 500 healthy individuals filled out the Persian version of the BAI and CESD-10 questionnaires. Multi-group multiple-indicators multiple-causes model (MG-MIMIC) was used to assess measurement invariance across PLWHAs and healthy people.

Results: Our findings revealed that PLWHAs and healthy individuals perceived the meaning of all the items in the BAI and CESD-10 questionnaires similarly. In addition, although depression scores were significantly higher in PLWHAs as opposed to the healthy individuals, no significant difference was observed in anxiety scores of these two groups.

Conclusions: The current study suggests that the BAI and CESD-10 are invariant measures across PLWHAs and healthy people which can be used for meaningful cross-group comparison. Therefore, in comparison to healthy individuals, higher depression score of PLWHAs is a real difference. It is highly recommended that health professionals develop therapeutic interventions and psychological supports to promote the mental health of PLWHAs which alleviate their depressive symptoms.
\end{abstract}

Keywords: Depression, Anxiety, Measurement invariance, PLWHA, Healthy population

\footnotetext{
*Correspondence: pjbiostat@gmail.com

1 Department of Biostatistics, School of Medicine, Shiraz University

of Medical Sciences, Shiraz, Iran

Full list of author information is available at the end of the article
}

\begin{abstract}
Background
A growing body of literature has highlighted that people living with HIV/AIDS (PLWHAs) experience a wide variety of distressing events such as complicated therapeutic regimes, disease exacerbation, shortened life expectancy, presence of pain, poor social and family support, financial burden as well as fear of disclosure and stigma [1-8]. Accordingly, it is not surprising
\end{abstract}


that depression and anxiety are highly prevalent among PLWHAs [2, 9-17]. The diagnosis and treatment of depression and anxiety in PLWHAs has received special attention in the past decade. The importance of this issue is underlined by the fact that the underdiagnosis and undertreatment of these psychological disorders usher in lower quality of life, poor adherence to HIV medications, faster disease progression, deterioration in immunological function, suicidal ideation, greater sexual risk behaviors, and marital conflict $[10,11,13$, $14,18-26]$. In general, the prevalence rate of depression and anxiety has been estimated from 3.2 to $45 \%$ and from 1.27 to $53 \%$ among PLWHAs, respectively $[2,9,12,27,28]$. This diversity in prevalence rates can be contributed to various populations of patients with HIV/AIDS in different studies, research settings and more importantly the methods and criteria used for the assessment and diagnosis of depression and anxiety.

Using Self-administered questionnaires is the most common method to measure depression and anxiety in the clinical and research settings. In recent years, a number of questionnaires have been introduced to assess these aforementioned psychological disorders in PLWHAs [29-33]. In addition to depression and anxiety diagnosis, researchers often use such measures to compare mean level of depression and anxiety between PLWHAs and other subpopulations, especially healthy population. As shown in previous studies, compared to the healthy population, PLWHAs had significantly higher depression and anxiety scores $[1-3,6]$. However, the validity of such cross-group comparisons depends on an important assumption which is known as measurement invariance. Measurement invariance means that different respondents from different groups perceive the meaning of the items in a given questionnaire similarly [34]. When measurement invariance does not hold, it is not clear whether the observed disparity in depression and anxiety scores between PLWHAs and healthy population is a real difference in the underlying construct of interest, or it is due to an artificial effect of different interpretations of items by PLWHAs and healthy individuals. Furthermore, pioneer researchers pointed out that in some subpopulations of chronic patients including HIV/AIDS, disentangling symptoms such as fatigue, sleep difficulties, and pain that are attributable to depression and anxiety as opposed to those that are owing to the disease or medication side effects is a challenging issue and segregation of their origin is onerous [13, 35]. Hence, it is of critical importance to investigate the measurement invariance of depression/anxiety questionnaires in PLWHA samples. If PLWHAs and healthy population perceive the meaning of the items of studied questionnaires in the same way, it can be concluded that the symptoms of depression and anxiety are not misinterpreted as the symptoms of the disease or medication side effects [35].

Although some studies have been carried out to investigate the measurement invariance of depression/anxiety questionnaires across various patient groups such as breast cancer, migration, neurologic patients, and healthy population [35-37], to the best of our knowledge, no study has been conducted to examine the measurement invariance of these questionnaires across PLWHAs and healthy population. To fill this gap, this study aims to evaluate the measurement invariance of the Beck Anxiety Inventory (BAI) and 10-item Centre for Epidemiological Studies Depression Scale (CESD-10) instruments across PLWHAs and healthy population.

\section{Methods}

\section{Participants}

All PLWHAs who referred to a voluntary counselling and testing (VCT) centre for preventive and medical care services, were invited to the study between February and June 2015 in Shiraz (Southern Iran). During the study period, 150 individuals participated in the study after filling out the consent forms. Patients who could read and write were included in the study; while those with neurocognitive impairment $(2.4 \%)$ were excluded. We collected some socio-demographic characteristics such as age, gender, job status, and education. In order to assess depression and anxiety of the patients, the Persian version of the CESD-10 and the BAI questionnaires were used, respectively.

Furthermore, a random sample of 500 healthy individuals were selected based on a two-stage cluster sampling technique across four educational districts located in diverse socioeconomic areas in the city of Shiraz. The data was collected from September to December 2015. In the first stage, a random sample of schools was selected from each educational district. Then, we selected one or two classes out of each school. A trained researcher distributed the CESD-10, BAI instruments, and the informed consent form to all students and asked them to give the questionnaires to their parents. Approximately, $70 \%$ (500 out of 700) of parents filled out the questionnaires at home after signing the informed consent form. In a couple of days, the completed questionnaires were turned back to school by children.

\section{Instruments}

\section{Beck Anxiety Inventory (BAI)}

The Persian version of the BAI questionnaire was used to measure anxiety in both PLWHAs and healthy individuals. The BAI is a self-report questionnaire that can reliably discriminate anxiety from depression. It comprises 21 anxiety symptoms that affected the participants during 
their last week. Individuals responded to the items on a 4-point Likert scale (from $0=$ 'not at all' to $3=$ 'severely, I could barely stand it'). The total score is the sum of all the items and ranges from 0 to 63, with a higher score showing greater anxiety [38]. The instrument was translated and validated previously in Persian which showed excellent internal consistency (Cronbach's alpha $=0.92$ ) and acceptable test-retest reliability $(r=0.72)$. The Persian version of the BAI also had stronger correlation $(r=0.40-0.44)$ with measures of anxiety as compared to measures of depression $(r=0.21)[39,40]$. The main reasons for selecting the BAI are its simplicity, briefness and widely use in clinical research. The original (English) version of the questionnaire is available at the following link: https://www.sciencedirect.com/topics/medicine-anddentistry/beck-anxiety-inventory.

\section{0-item Centre for Epidemiological Studies-Depression Scale (CESD-10)}

To measure the depression status of PLWHAs and healthy individuals, the Persian version of the CESD10 was applied [41]. It has been shown that the Persian version of the CESD-10 had acceptable internal consistency (Cronbach's alpha $=0.85$ ) and test-retest reliability $(r=0.65)$. It also showed good construct validity with the factor loadings of greater than 0.40 for all the items (41). According to previous research, this questionnaire is suitable to assess depression among PLWHAs. It is a short, easy to read and easy to score instrument which can reduce interview burden on the patients [33]. Moreover, it has been widely used for assessing depression symptoms in the general population. The items are scored on a 4-point Likert scale from 0 (not at all) to 3 (a lot). The total score is the sum of all the items with the possible range of 0 to 30 . The higher is the total score, the greater is the degree of depressive symptoms. The original (English) version of the questionnaire is available in the article by Zhang et al. (2012) [33].

\section{Statistical analysis}

Chi-square statistics and two-sided independent sample $t$ test were applied to investigate whether PLWHAs and healthy people differed significantly in terms of categorical and continuous demographic characteristics, respectively. $\mathrm{P}$ value $<0.05$ was considered as a significance level.

In the present study, the internal consistency of the CESD-10 and BAI questionnaires was assessed by Cronbach's alpha coefficient. A coefficient equal to or greater than 0.70 was considered to be a satisfactory level of reliability. Furthermore, prior to assessing measurement invariance, categorical confirmatory factor analysis (CCFA) was used to investigate the construct validity of the CESD-10 and BAI in both groups of healthy people and PLWHAs, separately. According to Thompson, the value of 0.3 was used as a factor loading criterion in this study [42]. Since a two-factor model was originally reported for the BAI by Beck [43], both one- and twofactor models were estimated to determine the best-fitting factor model in our sample.

The measurement invariance of a questionnaire is evaluated by differential item functioning (DIF) analysis. DIF occurs when people from different groups respond differently to a particular item given the same level of latent trait of interest. Two types of DIF can be identified, namely uniform and non-uniform DIF [34]. Uniform DIF means that on the entire continuum of the latent trait, item response probabilities are higher (lower) in one group compared to the other one. In contrast, in nonuniform DIF, the direction of DIF is different in different levels of latent trait [34].

In the present study, the multi-group multiple-indicators multiple-causes model (MG-MIMIC) was used to assess the measurement invariance of the BAI and CESD10 instruments across PLWHAs and healthy individuals. Technically, the MG-MIMIC model is an integration of multi-group confirmatory factor analysis (MGCFA) and MIMIC models that implements the same model constraints that are implicit in item response theory models $[44,45]$. This means that this model imitates the concepts of uniform and non-uniform DIF in item response theory to measurement non-invariance in factor analysis approach. In this model, uniform DIF is detected when discrepancy is observed in the thresholds of a given item across the groups and non-uniform DIF is identified when the factor loading of an item differs between the groups. In addition, in this technique the effects of confounding variables can also be controlled while assessing DIF $[44,45]$. In this study, the effects of age, gender and education which differed significantly between PLWHAs and healthy individuals were taken into account while examining DIF. In the MG-MIMIC model, DIF detection process is iterative and consists of serial tests of nested models, initiating with the most constrained model, consecutively relaxing cross-group equality constraints on the parameters, and then finishing up with the least constrained model.

In the first step, a baseline model which is the most constraint model is estimated. This model is fully invariant in factor loadings, thresholds, residual variance, latent trait variance and scaling factor across the groups. In this model, the only parameter which is freely estimated for both groups is the mean for latent trait, which allows estimating the group differences in underlying depression/anxiety. In step 2, the value of modification indices associated with factor loadings and thresholds 
in the baseline model is examined and the modification which would lead to the larger improvement in model fit is determined. If the modification index associated with thresholds of an item is larger than the others, this item is a candidate for uniform DIF. If the modification index associated with factor loading of an item is larger than the others, this may be an indication of non-uniform DIF item.

In step 3, the DIFFTEST procedure is used [46] to fit a model that relaxes the equality constraint on factor loadings across the groups relative to the baseline model. In step 4, the DIFFTEST procedure is used to fit a model that relaxes the equality constraint on item thresholds relative to the baseline model. In step 5 , the chi-square values from DIFFTEST procedure for these two modifications are compared and the larger one is identified; if it is significant, that modification is accepted and the other is rejected. If relaxing of factor loading parameter leads to larger improvement of the model and it is significant, non-uniform DIF is detected. While, if relaxing of thresholds parameter results in larger improvement and it is significant, uniform DIF is detected. In step 6, the resultant model in step 5 is considered as a new baseline model with the values of modification indices being examined again and all the steps mentioned above are repeated until no significant model modification is identified.

In order to assess the goodness of fit of the CCFA and MG-MIMIC models several indices were used including Chi-square statistics, root mean square error of approximation (RMSEA), Tucker-Lewis index (TLI), and comparative fit index (CFI). Although a non-significant value of Chi-square shows acceptable model fit, this index detects even trivial differences under large sample size. Hence, the other above-mentioned fit indices should also be considered for testing goodness of fit of the model. Values of CFI and TLI $>0.90$, and RMSEA $<0.08$ support that the model fit well [47]. In addition, for testing the relative fit of two nested models, $\Delta \chi^{2}, \Delta C F I$, and $\triangle$ RMSEA were used. According to Chen (2007), significant $\Delta \chi^{2}$, $\Delta \mathrm{CFI}>-0.01$, and $\triangle \mathrm{RMSEA}>0.015$ would indicate measurement non-invariance [48]. In the present study, the mean and variance-adjusted weighted least square (WLSMV) estimation procedure, which has been introduced for ordinal indicators, was applied to fit the CCFA and MG-MIMIC model using Mplus 6.1 software.

\section{Results}

Table 1 shows the summary statistics for demographic characteristics of the PLWHAs and healthy individuals. The mean age of healthy people $(42.67 \pm 6.78)$ was significantly greater than that of PLWHAs $(39.68 \pm 7.92)$. The percentage of male were significantly higher among PLWHAs as opposed to healthy people (64\% vs $50.6 \%$ ). In addition, the number of individuals with above diploma-level education was significantly higher among healthy population as compared to the PLWHAs (91.4\% vs $68.2 \%)$. However, there was no significant difference between healthy population and PLWHAs in terms of their employment status.

Table 2 represents the results of CCFA for assessing the construct validity of the CED-10 and BAI questionnaires as well as the Cronbach's alpha coefficient.

Table 1 Demographic characteristics of PLWHAs and healthy individuals

\begin{tabular}{|c|c|c|c|}
\hline \multirow[t]{2}{*}{ Variable } & PLWHA & Healthy & \\
\hline & Mean \pm SD & Mean \pm SD & Pvalue \\
\hline \multirow[t]{2}{*}{ Age } & $39.68 \pm 7.92$ & $42.67 \pm 6.78$ & $<0.001$ \\
\hline & Number (\%) & Number (\%) & $P$ value* \\
\hline \multicolumn{4}{|l|}{ Sex } \\
\hline Male & $96(64)$ & $253(50.6)$ & $<0.001$ \\
\hline Female & $54(36)$ & $247(49.4)$ & \\
\hline \multicolumn{4}{|l|}{ Education } \\
\hline Under diploma & $11(7.3)$ & $130(26)$ & $<0.001$ \\
\hline Above diploma & $137(91.4)$ & $341(68.2)$ & \\
\hline Missing & $2(1.3)$ & $29(5.8)$ & \\
\hline \multicolumn{4}{|l|}{ Job } \\
\hline Employed & $60(40)$ & $184(36.8)$ & 0.533 \\
\hline Unemployed & 77 (51.3) & $267(53.4)$ & \\
\hline Missing & $13(8.7)$ & $49(9.8)$ & \\
\hline
\end{tabular}

*p value based on Chi-square statistics

^ $\mathrm{P}$ value based on independent samples $\mathrm{t}$ test 
Table 2 Goodness of fit indices for CCFA model and Cronbach's alpha coefficient for CESD-10 and BAI questionnaires in healthy people and PLWHAs

\begin{tabular}{lllllll}
\hline Questionnaire & Group & $X^{2}(\mathrm{df}), \mathrm{P}$ & CFI & TLI & RMSEA & Cronbach's alpha \\
\hline CESD-10 & Healthy & $162.62(33),<0.001$ & 0.96 & 0.94 & 0.080 & 0.74 \\
\multirow{2}{*}{ One-factor BAI } & PLWHA & $54.36(32), 0.008$ & 0.97 & 0.96 & 0.068 & 0.75 \\
& Healthy & $593.54(189),<0.001$ & 0.95 & 0.94 & 0.057 & 0.91 \\
Two-factor BAI & PLWHA & $332.03(189),<0.001$ & 0.94 & 0.93 & 0.071 & 0.91 \\
& Healthy & $590.96(188),<0.001$ & 0.95 & 0.94 & 0.057 & 0.91 \\
& PLWHA & $329.53(188),<0.001$ & 0.94 & 0.93 & 0.071 & 0.91 \\
\hline
\end{tabular}

As indicated, the magnitudes of goodness of fit indices supported the one-factor model for the CESD-10 in both healthy people (RMSEA $=0.08, \mathrm{CFI}=0.96$, $\mathrm{TLI}=0.94)$ and PLWHAs (RMSEA $=0.068, \mathrm{CFI}=0.97$, $\mathrm{TLI}=0.96$ ). In addition, the factor loadings of all the items were significant and higher than 0.3 in both groups except for that of item 4 in PLWHAs which was 0.245 (The full results are not presented here due to the space limitation). Interestingly, for the BAI questionnaire, both one- and two-factor models fit equally well in healthy people (RMSEA $=0.057, \mathrm{CFI}=0.95$, $\mathrm{TLI}=0.94)$ and PLWHAs (RMSEA $=0.071, \mathrm{CFI}=0.94$, $\mathrm{TLI}=0.93$ ). The factor loadings of all the items were significant and higher than 0.50 in both groups (The full results are not presented here due to the space limitation). In addition, the Cronbach's alpha coefficients for the CESD-10 were 0.74 and 0.75 for healthy people and PLWHs, respectively. For the BAI, the Cronbach's alpha value was 0.91 for both groups.

Table 3 shows the results of the MG-MIMIC model including the factor loadings and thresholds of the items in the CESD-10 questionnaire across PLWHAs and healthy people. As indicated the factor loadings and thresholds of all the items were equal between PLWHAs and healthy individuals which implies that there was no DIF item across the groups and measurement invariance of the CESD-10 was established. The values of fit indices (RMSEA $=0.069, \mathrm{CFI}=0.94$, and TLI $=0.94$ ) also confirmed that the most constraint model fit well to the data. It should be noted that although the values of modification indices associated with all factor loadings and thresholds were small in the most constraint model, we proceeded with the next steps to investigate that whether relaxing equality constraints can lead to further improvement of the model fit and any DIF item can be detected. The largest modification index among factor loadings was associated with item 6 (modification index $=4.61$ ); consequently, the equality constraint of this factor loading was relaxed and the resultant model was compared with the baseline model based on DIFFTEST procedure. The values of $\Delta X^{2}(\Delta \mathrm{df}), \Delta C F I$, and $\Delta$ RMSEA were $1.66(1)$, $-0.001,0.001$, respectively, suggesting that no modification was needed and this item was not a candidate for non-uniform DIF. The largest modification index among thresholds was associated with item 9 (modification index $=2.59$ ); hence, the equality constraint on this item thresholds was relaxed and the resulting model was compared with the baseline model based on DIFFTEST procedure. The values of $\Delta \chi^{2}(\Delta \mathrm{df})=5.91(3)$, $\Delta \mathrm{CFI}=-0.0001$, and $\triangle \mathrm{RMSEA}=0.001$ indicated that no significant improvement was observed and this item cannot be considered as uniform DIF. Since neither of the difference testing results produced a statistically significant improvement in model fit, we then stopped the algorithm.

Table 4 represents the estimated factor loadings and thresholds of the one-factor BAI's items resulting from the MG-MIMIC model for assessing DIF across PLWHAs and healthy individuals. As shown the values of factor loadings and thresholds of all the items were the same across the groups. This means that no DIF item was detected and the BAI is an invariant questionnaire across PLWHAs and healthy individuals. In addition, the values of fit indices supported the fit of the most constraint model $($ RMSEA $=0.064, C F I=0.95$, and TLI $=0.96)$. The values of modification indices associated with all factor loadings and thresholds were small in the most constraint model. Nevertheless, we continued to the next steps. The largest modification index among factor loadings was associated with item 17 (modification index $=10.69$ ); consequently, the equality constraint of this factor loading was relaxed across the groups and the resultant model was compared with the baseline model based on DIFFTEST procedure. The values of $\Delta \chi^{2}(\Delta \mathrm{df}), \Delta C F I$, and $\Delta$ RMSEA were $3.41(1),-0.0001,0.0001$, respectively, indicating that no significant improvement was observed and this item cannot be considered as non-uniform DIF. The largest modification index among thresholds was associated with item 13 (modification index $=1.54$ ); 
Table 3 Item parameters and standard errors for the items in the CESD-10 questionnaire across PLWHAs and healthy population

\begin{tabular}{|c|c|c|c|c|}
\hline & $\begin{array}{l}\text { Factor loading } \\
\text { b (SE) }\end{array}$ & $\begin{array}{l}\text { 1st threshold } \\
\tau_{1}(S E)\end{array}$ & $\begin{array}{l}\text { 2nd threshold } \\
\tau_{2}(S E)\end{array}$ & $\begin{array}{l}\text { 3rd threshold } \\
\tau_{3}(S E)\end{array}$ \\
\hline \multicolumn{5}{|c|}{ q1: I was bothered by things that usually don't bother me } \\
\hline Healthy & $0.870(0.077)$ & $-1.111(0.470)$ & $0.007(0.469)$ & $0.888(0.473)$ \\
\hline PLWHA & $0.870(0.077)$ & $-1.111(0.470)$ & $0.007(0.469)$ & $0.888(0.473)$ \\
\hline \multicolumn{5}{|c|}{ q2: I had trouble keeping my mind on what I was doing } \\
\hline Healthy & $0.841(0.073)$ & $-0.849(0.494)$ & $0.435(0.492)$ & $1.072(0.508)$ \\
\hline PLWHA & $0.841(0.073)$ & $-0.849(0.494)$ & $0.435(0.492)$ & $1.072(0.508)$ \\
\hline \multicolumn{5}{|c|}{ q3: I felt depressed } \\
\hline Healthy & $1.492(0.124)$ & $-2.447(0.678)$ & $-1.094(0.668)$ & $-0.004(0.668)$ \\
\hline PLWHA & $1.492(0.124)$ & $-2.447(0.678)$ & $-1.094(0.668)$ & $-0.004(0.668)$ \\
\hline \multicolumn{5}{|c|}{ q4: I felt that everything I did was an effort } \\
\hline Healthy & $0.268(0.049)$ & $1.025(0.334)$ & $0.382(0.330)$ & $-0.246(0.331)$ \\
\hline PLWHA & $0.268(0.049)$ & $1.025(0.334)$ & $0.382(0.330)$ & $-0.246(0.331)$ \\
\hline \multicolumn{5}{|c|}{ q5: I felt hopeful about the future } \\
\hline Healthy & $0.654(0.062)$ & $-1.190(0.398)$ & $-0.469(0.396)$ & $0.115(0.399)$ \\
\hline PLWHA & $0.654(0.062)$ & $-1.190(0.398)$ & $-0.469(0.396)$ & $0.115(0.399)$ \\
\hline \multicolumn{5}{|c|}{ q6: I felt fearful } \\
\hline Healthy & $1.036(0.087)$ & $-1.354(0.539)$ & $-0.320(0.537)$ & $0.535(0.539)$ \\
\hline PLWHA & $1.036(0.087)$ & $-1.354(0.539)$ & $-0.320(0.537)$ & $0.535(0.539)$ \\
\hline \multicolumn{5}{|c|}{ q7: My sleep was restless } \\
\hline Healthy & $1.006(0.080)$ & $-0.443(0.522)$ & $0.610(0.523)$ & $1.488(0.538)$ \\
\hline PLWHA & $1.006(0.080)$ & $-0.443(0.522)$ & $0.610(0.523)$ & $1.488(0.538)$ \\
\hline \multicolumn{5}{|c|}{ q8: I was happy } \\
\hline Healthy & $0.824(0.066)$ & $-1.887(0.408)$ & $-0.741(0.403)$ & $0.298(0.404)$ \\
\hline PLWHA & $0.824(0.066)$ & $-1.887(0.408)$ & $-0.741(0.403)$ & $0.298(0.404)$ \\
\hline \multicolumn{5}{|c|}{ q9: I felt lonely } \\
\hline Healthy & $1.092(0.088)$ & $-1.521(0.523)$ & $-0.435(0.520)$ & $0.505(0.526)$ \\
\hline PLWHA & $1.092(0.088)$ & $-1.521(0.523)$ & $-0.435(0.520)$ & $0.505(0.526)$ \\
\hline \multicolumn{5}{|c|}{ q10: I could not "get going" } \\
\hline Healthy & $1.264(0.116)$ & $-1.192(0.592)$ & $-0.266(0.593)$ & $0.648(0.600)$ \\
\hline PLWHA & $1.264(0.116)$ & $-1.192(0.592)$ & $-0.266(0.593)$ & $0.648(0.600)$ \\
\hline
\end{tabular}

$\mathrm{b}$ : factor loading, $\mathrm{\tau}_{\mathrm{i}}$ : threshold parameters, $\mathrm{SE}$ : standard error

hence, the model that relaxed equality constraint on this item threshold was fitted and compared with the baseline model based on DIFFTEST procedure. The values of $\Delta \mathrm{X}^{2}$ $(\Delta \mathrm{df})=3.14(3), \Delta \mathrm{CFI}=-0.0001$, and $\triangle \mathrm{RMSEA}=0.0001$ suggested that no significant change was detected in model fit and this item cant not be considered as uniform DIF. Therefore, we stopped the algorithm since neither of the difference testing results produced a statistically significant improvement in model fit.

It should be noted that assessing DIF was also investigated for the two-factor BAI. The findings showed that the magnitudes of fit indices were exactly the same as one-factor model and the estimated parameters were very close to those represented in Table 4 (not reported here).
Table 5 represents the depression and anxiety scores (mean \pm SD) of PLWHAs and healthy individuals. Although the anxiety scores did not differ significantly between these two groups, the depression scores of PLWHAs were significantly higher than those of healthy individuals.

\section{Discussion}

The current study investigated the measurement invariance of the CESD-10 and BAI across PLWHAs and healthy individuals, the issue which has never been investigated in the previous studies. Our findings provide evidence that the measurement invariance for valid comparison across healthy individuals and PLWHAs has been satisfied for the CESD-10 and BAI questionnaires. This 
Table 4 Item parameters and standard errors for the items in the BAl questionnaire across PLWHAs and healthy general population

\begin{tabular}{|c|c|c|c|c|}
\hline & $\begin{array}{l}\text { Factor loading } \\
\mathrm{b}(\mathrm{SE})\end{array}$ & $\begin{array}{l}\text { 1st threshold } \\
\tau_{1}(S E)\end{array}$ & $\begin{array}{l}2^{\text {nd }} \text { threshold } \\
\tau_{2}(S E)\end{array}$ & $\begin{array}{l}\text { 3rd threshold } \\
\tau_{3}(\mathrm{SE})\end{array}$ \\
\hline \multicolumn{5}{|c|}{ q1: Numbness or tingling } \\
\hline Healthy & $0.887(0.072)$ & $0.442(0.481)$ & $1.615(0.479)$ & $2.846(0.518)$ \\
\hline PLWHA & $0.887(0.072)$ & $0.442(0.481)$ & $1.615(0.479)$ & $2.846(0.518)$ \\
\hline \multicolumn{5}{|c|}{ q2: Feeling hot } \\
\hline Healthy & $0.797(0.061)$ & $0.024(0.441)$ & $0.922(0.443)$ & $2.387(0.446)$ \\
\hline PLWHA & $0.797(0.061)$ & $0.024(0.441)$ & $0.922(0.443)$ & $2.387(0.446)$ \\
\hline \multicolumn{5}{|c|}{ q3: Wobbliness in legs } \\
\hline Healthy & $1.089(0.095)$ & $0.277(0.630)$ & $1.025(0.634)$ & $2.222(0.666)$ \\
\hline PLWHA & $1.089(0.095)$ & $0.277(0.630)$ & $1.025(0.634)$ & $2.222(0.666)$ \\
\hline \multicolumn{5}{|c|}{ 94: Unable to relax } \\
\hline Healthy & $1.115(0.077)$ & $-0.521(0.550)$ & $0.818(0.554)$ & $2.083(0.570)$ \\
\hline PLWHA & $1.115(0.077)$ & $-0.521(0.550)$ & $0.818(0.554)$ & $2.083(0.570)$ \\
\hline \multicolumn{5}{|c|}{ q5: Fear of worst happening } \\
\hline Healthy & $0.891(0.060)$ & $-0.519(0.473)$ & $0.459(0.476)$ & $1.822(0.490)$ \\
\hline PLWHA & $0.891(0.060)$ & $-0.519(0.473)$ & $0.459(0.476)$ & $1.822(0.490)$ \\
\hline \multicolumn{5}{|c|}{ q6: Dizzy or lightheaded } \\
\hline Healthy & $1.163(0.086)$ & $-0.927(0.671)$ & $0.126(0.678)$ & $1.588(0.731)$ \\
\hline PLWHA & $1.163(0.086)$ & $-0.927(0.671)$ & $0.126(0.678)$ & $1.588(0.731)$ \\
\hline \multicolumn{5}{|c|}{ q7: Heart pounding/racing } \\
\hline Healthy & $1.071(0.075)$ & $0.430(0.583)$ & $1.550(0.587)$ & $2.716(0.598)$ \\
\hline PLWHA & $1.071(0.075)$ & $0.430(0.583)$ & $1.550(0.587)$ & $2.716(0.598)$ \\
\hline \multicolumn{5}{|c|}{ q8: Unsteady } \\
\hline Healthy & $1.130(0.091)$ & $0.642(0.587)$ & $1.888(0.579)$ & $2.957(0.629)$ \\
\hline PLWHA & $1.130(0.091)$ & $0.642(0.587)$ & $1.888(0.579)$ & 2.957 (0.629) \\
\hline \multicolumn{5}{|c|}{ 99: Terrified or afraid } \\
\hline Healthy & $1.105(0.087)$ & $0.463(0.628)$ & $1.410(0.619)$ & $2.869(0.706)$ \\
\hline PLWHA & $1.105(0.087)$ & $0.463(0.628)$ & $1.410(0.619)$ & $2.869(0.706)$ \\
\hline \multicolumn{5}{|c|}{ 910: Nervous } \\
\hline Healthy & $0.914(0.060)$ & $-1.039(0.482)$ & $0.064(0.481)$ & $1.698(0.496)$ \\
\hline PLWHA & $0.914(0.060)$ & $-1.039(0.482)$ & $0.064(0.481)$ & $1.698(0.496)$ \\
\hline \multicolumn{5}{|c|}{ q11: Feeling of choking } \\
\hline Healthy & $1.251(0.132)$ & $0.151(0.812)$ & $1.135(0.806)$ & $2.233(0.865)$ \\
\hline PLWHA & $1.251(0.132)$ & $0.151(0.812)$ & $1.135(0.806)$ & $2.233(0.865)$ \\
\hline \multicolumn{5}{|c|}{ 912: Hands trembling } \\
\hline Healthy & $0.985(0.084)$ & $-0.153(0.572)$ & $0.748(0.571)$ & $2.089(0.646)$ \\
\hline PLWHA & $0.985(0.084)$ & $-0.153(0.572)$ & $0.748(0.571)$ & $2.089(0.646)$ \\
\hline \multicolumn{5}{|c|}{ q13: Shaky/unsteady } \\
\hline Healthy & $1.360(0.144)$ & $-0.163(0.801))(0.084)$ & $0.913(0.797)$ & $2.119(0.896)$ \\
\hline PLWHA & $1.360(0.144)$ & $-0.163(0.801))(0.084)$ & $0.913(0.797)$ & $2.119(0.896)$ \\
\hline \multicolumn{5}{|c|}{ 914: Fear of losing control } \\
\hline Healthy & $0.868(0.072)$ & $-1.155(0.536)$ & $-0.044(0.525)$ & $1.263(0.592)$ \\
\hline PLWHA & $0.868(0.072)$ & $-1.155(0.536)$ & $-0.044(0.525)$ & $1.263(0.592)$ \\
\hline \multicolumn{5}{|c|}{ 915: Difficulty in breathing } \\
\hline Healthy & $1.161(0.115)$ & $0.227(0.852)$ & $1.429(0.841)$ & $2.436(0.900)$ \\
\hline PLWHA & $1.161(0.115)$ & $0.227(0.852)$ & $1.429(0.841)$ & $2.436(0.900)$ \\
\hline \multicolumn{5}{|c|}{ q16: Fear of dying } \\
\hline Healthy & $0.539(0.058)$ & $-0.698(0.411)$ & $-0.068(0.406)$ & $0.838(0.414)$ \\
\hline PLWHA & $0.539(0.058)$ & $-0.698(0.411)$ & $-0.068(0.406)$ & $0.838(0.414)$ \\
\hline
\end{tabular}


Table 4 (continued)

\begin{tabular}{|c|c|c|c|c|}
\hline & $\begin{array}{l}\text { Factor loading } \\
\mathrm{b}(\mathrm{SE})\end{array}$ & $\begin{array}{l}\text { 1st threshold } \\
\tau_{1}(S E)\end{array}$ & $\begin{array}{l}2^{\text {nd }} \text { threshold } \\
\tau_{2}(S E)\end{array}$ & $\begin{array}{l}\text { 3rd threshold } \\
\tau_{3}(S E)\end{array}$ \\
\hline \multicolumn{5}{|c|}{ 917: Scared } \\
\hline Healthy & $0.854(0.071)$ & $-0.262(0.514)$ & $0.849(0.508)$ & $1.917(0.537)$ \\
\hline PLWHA & $0.854(0.071)$ & $-0.262(0.514)$ & $0.849(0.508)$ & $1.917(0.537)$ \\
\hline \multicolumn{5}{|c|}{ q18: Indigestion } \\
\hline Healthy & $0.800(0.069)$ & $0.421(0.498)$ & $1.339(0.496)$ & $2.359(0.529)$ \\
\hline PLWHA & $0.800(0.069)$ & $0.421(0.498)$ & $1.339(0.496)$ & $2.359(0.529)$ \\
\hline \multicolumn{5}{|c|}{ q19: Faint/lightheaded } \\
\hline Healthy & $1.557(1.262)$ & $1.740(1.280)$ & $1.470(1.212) 143.472$ & $2.853(2.245)$ \\
\hline PLWHA & $1.557(1.262)$ & $1.740(1.280)$ & $1.470(1.212) 143.472$ & $2.853(2.245)$ \\
\hline \multicolumn{5}{|c|}{ q20: Face flushed } \\
\hline Healthy & $0.626(0.064)$ & $1.290(0.508)$ & $2.208(0.514)$ & $2.986(0.520)$ \\
\hline PLWHA & $0.626(0.064)$ & $1.290(0.508)$ & $2.208(0.514)$ & $2.986(0.520)$ \\
\hline \multicolumn{5}{|c|}{ q21: Hot/cold sweats } \\
\hline Healthy & $0.785(0.066)$ & $0.577(0.463)$ & $1.329(0.463)$ & $2.573(0.470)$ \\
\hline PLWHA & 0.785 (0.066) & $0.577(0.463)$ & $1.329(0.463)$ & $2.573(0.470)$ \\
\hline
\end{tabular}

b: factor loading, $\mathrm{\tau}_{\mathrm{i}}$ : threshold parameters, $\mathrm{SE}$ : standard error

Table 5 Comparison of depression and anxiety scores between PLWHAs and healthy individuals

\begin{tabular}{lclr}
\hline Variable & PLWHA & Healthy & \\
& Mean \pm SD & Mean \pm SD & Pvalue $^{\text {P }}$ \\
\hline Depression & $10.45 \pm 5.56$ & $7.16 \pm 4.95$ & $<0.001$ \\
Anxiety & $8.34 \pm 8.02$ & $8.36 \pm 8.12$ & 0.974 \\
\hline
\end{tabular}

" $\mathrm{P}$ value based on independent samples $t$ test

implies that PLWHAs and healthy individuals perceived the meaning of the items in the CESD-10 and BAI questionnaires similarly. Furthermore, it can be concluded that the symptoms of depression and anxiety could not be misinterpreted as the symptoms of the disease or the side effects of medication.

Previous studies assessing the measurement invariance of several depression and anxiety questionnaires across healthy individuals and patients with different chronic conditions have reached conflicting results. In accordance with the results of the present study, some previous research has demonstrated the measurement invariance of the CESD, PHQ-9, PROMISD-8, K6 and GDS-15 across community sample and patients with neurologic, cognitive as well as arthritis problems [35, 49-51]. In contrast, Broekman et al. (2008) detected some items with DIF in GDS-15 questionnaire across healthy individuals and people with chronic illness [52]. In addition, in a study which examined the measurement invariance of the PHQ-9 across healthy individuals and patients with breast, lung, and colorectal cancers, two items with DIF were identified. Waller et al. (2005) also reported differential item functioning of Beck Depression Inventory questionnaire across women with breast cancers and women with major depression disorder [53]. Furthermore, it has been shown that Short Health Anxiety Inventory questionnaire was not an invariant measure across healthy individuals and patients with diabetes, breast cancer along with multiple sclerosis [36]. These contradictory results may be due to different questionnaires which have been applied in different studies as well as various kinds of health conditions studied in previous research.

It should be also noted that there is no consensus on factor structure of the BAI in previous studies. Although Beck (1988) originally reported a two-factor model for this instrument [43] thereafter, several studies have proposed different factor structures from one-factor to even five-factor model in different cultures [40, 54-56]. This issue may also lead to contrasting results in DIF assessment. In the present study, we considered the one-factor BAI based on the results of previous studies in Iran indicating that the one-factor model provided the best fit for the Persian version of the BAI $[39,40]$. However, our findings supported both one- and two-factor models based on CCFA; more importantly, the results of DIF analysis was the same for both models.

Another important finding of the present study is that depression scores were significantly higher among PLWHAs as compared to healthy individuals. This result supports previous studies [1, 2, 57]. According to the proceeding research, stigma, poor family relations, limited psychological support, and lower socioeconomic status 
may explain the increased risk of depression in PLWHAs $[1,2,21,58-60]$.

Contrary to our expectations, this study showed that no significant difference was observed between anxiety scores of PLWHAs and healthy individuals. Although this result differs from some published studies which reported that anxiety was higher in PLWHAs as opposed to the general population $[1-3,6,14,57]$, it is consistent with other studies such as Prasithsirikul et al. (2017) and Sewell et al. (2000) $[28,60]$. These contradictions in the results could be attributed to a variety of populations and instruments applied in different studies to ascertain the diagnosis of psychological disorders. One possible explanation for our findings might be that the mean duration of living with HIV in our sample was $5.52 \pm 3.43$ which is somehow a lengthy period in which PLWHAs have acquired skills to adapt to living with HIV so that they may no longer be afraid of dying from HIV $[28,60]$.

It is worth to mention some key advantages of using MG-MIMIC model in DIF assessment. First, as compared with MGCFA model, MG-MIMIC was able to control the potential confounding variables such as age, gender, and education which may affect the results of DIF analysis between healthy individuals and PLWHAs [44]. Second, unlike the MIMIC model, MG-MIMIC was able to detect non-uniform DIF in addition to uniform DIF. In addition, the purification of anchor items is another superiority of MG-MIMIC model in DIF detection process. The importance of this issue is due to the fact that ignoring purification results in over- or under-estimation in the number of DIF items [44, 45].

This study has some limitations that merit attention when interpreting the results. First, the factor loading of item 4 in the CESD-10 was lower than the suggested cut-point of 0.30 . However, this result has not previously been described in a study examining the construct validity of the CESD-10 among PLWHAs in Canada [33]. Consequently, it would be beneficial to investigate the construct validity of the CESD-10 in the same sample in other languages and cultural contexts. Second, the sample of patients was gender-imbalance as the majority of PLWHAs was male. The result would be different if we matched PLWHAs and healthy individuals in terms of their gender. Moreover, the results of DIF may differ from one questionnaire to another; therefore, further investigations should be conducted to assess the measurement invariance of other depression and anxiety questionnaires. Different results would also be achieved if we assessed DIF among participants with other cultures, nationalities, or health conditions which can be an important issue for further research. Finally, Woods suggested that for reasonably powerful and accurate MIMIC results, sample size of focal (patients) group should be at least 100 with reference (healthy) group sample size of 500 [61]. Since no simulation study has been conducted regarding the sample size requirement in the MGMIMIC model, we followed this outline for sample size determination in our study. It would be fruitful to investigate this important issue in future studies, too.

\section{Conclusions}

In conclusion, the findings of this study suggest that the BAI and CESD-10 questionnaires can be considered as invariant measures across PLWHAs and healthy individuals, at least in our sample. More importantly, the measurement invariance of the questionnaires may ensure us that the higher depression scores of PLWHAs in comparison to healthy individuals is a real difference. It is highly recommended that health professionals develop therapeutic interventions and psychological supports to promote the mental health of PLWHAs that alleviate their depression symptoms.

\begin{abstract}
Abbreviations
BAl: Beck Anxiety Inventory; CESD-10: 10-Item Centre for Epidemiological Studies Depression Scale; PLWHA: People living with HIV/AIDS; MG-MIMIC: Multi-group multiple-indicator multiple-causes; VCT: Voluntary counselling and testing centre; DIF: Differential item functioning; RMSEA: Root mean square error of approximation; TLI: Tucker-Lewis index; CFI: Comparative fit index; WLSMV: Mean and variance-adjusted weighted least square.
\end{abstract}

\section{Acknowledgements}

We would like to express our special thanks to the Shiraz University of Medical Sciences that allowed us to conduct this study. We are also grateful to Dr Nasrin Motazedian for her support in data gathering process.

\section{Authors' contributions}

ZB designed the study, analyzed the data, interpreted the results and wrote the manuscript. PN collected and analyzed the data, and wrote some parts of the manuscript. ZSH wrote some parts of the manuscript and edited the manuscript in terms of English language. PJ designed the study, analyzed the data, interpreted the results and wrote the manuscript. All authors read and approved the final manuscript.

\section{Funding}

This work was supported by a grant from Shiraz University of Medical Sciences Research Council (95-01-01-11661). The university had no role in the design of the study, data collection, analysis, interpretation of data, and writing the manuscript. The article was extracted from Pegah Noorshargh's Master of Science thesis.

\section{Availability of data and materials}

The datasets used and analyzed during the current study is available from the corresponding author on reasonable request (pjbiostat@gmail.com).

\section{Declarations}

\section{Ethics approval and consent to participate}

The study was approved by the ethical and research committee of Shiraz University of Medical Sciences (IR.SUMS.REC.1395.S1006). All the procedures performed in the study were in accordance with the 1964 Helsinki declaration and its later amendments to ethical standards. A signed informed consent form was obtained from all participants prior to starting the data collection. 


\section{Competing interests}

The authors declare that they have no competing interests.

\section{Author details}

${ }^{1}$ Department of Biostatistics, School of Medicine, Shiraz University of Medical Sciences, Shiraz, Iran. ${ }^{2}$ Department of English Language, Shiraz University of Medical Sciences, Shiraz, Iran.

\section{Received: 21 September 2020 Accepted: 2 March 2021} Published online: 09 March 2021

\section{References}

1. Charles B, Jeyaseelan L, Pandian AK, Sam AE, Thenmozhi M, Jayaseelan V. Association between stigma, depression and quality of life of people living with HIV/AIDS (PLHA) in South India - a community based cross sectional study. BMC Public Health. 2012;12:463.

2. Hellmuth J, Colby D, Valcour V, Suttichom D, Spudich S, Ananworanich J, et al. Depression and anxiety are common in acute HIV infection and associate with plasma immune activation. AIDS Behav. 2017;21:3238-46.

3. Junqueira P, Bellucci S, Rossini S, Reimao R. Women living with HIV/AIDS: sleep impairment, anxiety and depression symptoms. Arq Neuropsiquiatr. 2008:66:817-20.

4. Li L, Liang LJ, Ding YY, Ji G. Facing HIV as a family: predicting depressive symptoms with correlated responses. J Fam Psychol. 2011;25:202-9.

5. Li L, Wu Z, Wu S, Jia M, Lieber E, Lu Y. Impacts of HIV/AIDS stigma on family identity and interactions in China. Fam Syst Health. 2008:26:431-42.

6. Morrison SD, Banushi VH, Sarnquist C, Gashi VH, Osterberg L, Maldonado $Y$, et al. Levels of self-reported depression and anxiety among HIV-positive patients in Albania: a cross-sectional study. Croat Med J. 2011:52:622-8.

7. Tesfaw G, Ayano G, Awoke T, Assefa D, Birhanu Z, Miheretie G, et al. Prevalence and correlates of depression and anxiety among patients with HIV on-follow up at Alert Hospital, Addis Ababa. Ethiopia BMC Psychiatry. 2016:16:368.

8. Valente SM. Depression and HIV disease. J Assoc Nurses AIDS Care. 2003; 14:41-51.

9. Basu S, Chwastiak LA, Bruce RD. Clinical management of depression and anxiety in HIV-infected adults. AIDS. 2005;19:2057-67.

10. Betancur MN, Lins L, Oliveira IR, Brites C. Quality of life, anxiety and depression in patients with HIV/AIDS who present poor adherence to antiretroviral therapy: a cross-sectional study in Salvador. Brazil Braz J Infect Dis. 2017;21:507-14.

11. Chandra PS, Ravi V, Desai A, Subbakrishna DK. Anxiety and depression among HIV-infected heterosexuals - a report from India. J Psychosom Res. 1998:45:401-9.

12. Elliott A. Anxiety and HIV infection STEP perspective. 1998;98:11-4.

13. Gonzalez A, Zvolensky MJ, Parent J, Grover KW, Hickey M. HIV symptom distress and anxiety sensitivity in relation to panic, social anxiety, and depression symptoms among HIV-positive adults. AIDS Patient Care STDS. 2012;26:156-64.

14. Kemppainen JK, MacKain S, Reyes D. Anxiety symptoms in HIV-infected individuals. J Assoc Nurses AIDS Care. 2013:24(Suppl 1):S29-39.

15. Nacher M, Adriouch L, Godard Sebillotte C, Hanf M, Vantilcke V, El Guedj $\mathrm{M}$, et al. Predictive factors and incidence of anxiety and depression in a cohort of HIV-positive patients in French Guiana. AIDS Care. 2010:22:1086-92.

16. Perdices M, Dunbar N, Grunseit A, Hall W, Cooper DA. Anxiety, depression and HIV related symptomatology across the spectrum of HIV disease. Aust N Z J Psychiatry. 1992;26:560-6.

17. Savard J, Laberge B, Gauthier JG, Ivers H, Bergeron MG. Evaluating anxiety and depression in HIV-infected patients. J Pers Assess. 1998;71:349-67.

18. Collins PY, Holman AR, Freeman MC, Patel V. What is the relevance of mental health to HIV/AIDS care and treatment programs in developing countries? A systematic review. AIDS. 2006;20:1571-82

19. Evans DL, Leserman J, Perkins DO, Stern RA, Murphy C, Zheng B, et al. Severe life stress as a predictor of early disease progression in HIV infection. Am J Psychiatry. 1997:154:630-4.

20. Himelhoch S, Moore RD, Treisman G, Gebo KA. Does the presence of a current psychiatric disorder in AIDS patients affect the initiation of antiretroviral treatment and duration of therapy? J Acquir Immune Defic Syndr. 2004;37:1457-63.

21. Lyketsos CG, Hoover DR, Guccione M, Senterfitt W, Dew MA, Wesch J, et al. Depressive symptoms as predictors of medical outcomes in HIV infection. Multicenter AIDS Cohort Study JAMA. 1993;270:2563-7.

22. Olisah VO, Baiyewu O, Sheikh TL. Depression underdiagnosis and the effects on quality of life in outpatients with HIV at a Nigerian University Teaching Hospital. Afr J AIDS Res. 2011;10:247-54.

23. Reis RK, Haas VJ, Santos CB, Teles SA, Galvao MT, Gir E. Symptoms of depression and quality of life of people living with HIV/AIDS. Rev Lat Am Enfermagem. 2011;19:874-81.

24. Wagner GJ, Kanouse DE, Koegel P, Sullivan G. Adherence to HIV antiretrovirals among persons with serious mental illness. AIDS Patient Care STDS. 2003:17:179-86.

25. Zena-Castillo D, Mezones-Holguin E, Valdiviezo-Garcia G, La-Chira-Alban A, Rodriguez-Morales AJ, Dickson-Gonzalez S. Impact of hospitalassociated anxiety and depression on the CD4 counts of naive HIV/AIDS patients from locations in Northern Peru. Int J Infect Dis. 2009;13:e75-6.

26. Zimpel RR, Fleck MP. Depression as a major impact on the quality of life of HIV-positive Brazilians. Psychol Health Med. 2014;19:47-58.

27. Bing EG, Burnam MA, Longshore D, Fleishman JA, Sherbourne CD, London AS, et al. Psychiatric disorders and drug use among human immunodeficiency virus-infected adults in the United States. Arch Gen Psychiatry. 2001;58:721-8.

28. Prasithsirikul W, Chongthawonsatid S, Ohata PJ, Keadpudsa S, Klinbuayaem $V$, Rerksirikul P, et al. Depression and anxiety were low amongst virally suppressed, long-term treated HIV-infected individuals enrolled in a public sector antiretroviral program in Thailand. AIDS Care. 2017;29:299-305.

29. Reda AA. Reliability and Validity of the Ethiopian Version of the Hospital Anxiety and Depression Scale (HADS) in HIV infected patients. PLoS ONE. 2011;6:e16049.

30. Robertson K, Bayon C, Molina JM, McNamara P, Resch C, Munoz-Moreno JA, et al. Screening for neurocognitive impairment, depression, and anxiety in HIV-infected patients in Western Europe and Canada. AIDS Care. 2014;26:1555-61.

31. Spies G, Kader K, Kidd M, Smit J, Myer L, Stein DJ, et al. Validity of the K-10 in detecting DSM-IV-defined depression and anxiety disorders among HIV-infected individuals. AIDS Care. 2009;21:1163-8.

32. Wouters E, Booysen Fle R, Ponnet K, Baron Van Loon F. Wording effects and the factor structure of the Hospital Anxiety \& Depression Scale in HIV/AIDS patients on antiretroviral treatment in South Africa. PLoS ONE. 2012;7:e34881.

33. Zhang W, O'Brien N, Forrest Jl, Salters KA, Patterson TL, Montaner JS, et al. Validating a shortened depression scale (10 item CES-D) among HIVpositive people in British ColumBAl, Canada. PLoS ONE. 2012;7:e40793.

34. Teresi JA, Fleishman JA. Differential item functioning and health assessment. Qual Life Res. 2007;16(Suppl 1):33-42.

35. Chung H, Kim J, Askew RL, Jones SM, Cook KF, Amtmann D. Assessing measurement invariance of three depression scales between neurologic samples and community samples. Qual Life Res. 2015;24:1829-34.

36. LeBouthillier DM, Thibodeau MA, Alberts NM, Hadjistavropoulos HD, Asmundson GJ. Do people with and without medical conditions respond similarly to the short health anxiety inventory? An assessment of differential item functioning using item response theory. J Psychosom Res. 2015;78:384-90.

37. Maksimovic S, Ziegenbein M, Machleidt W, Sieberer M. Measurement invariance of the German version of the Center for Epidemiological Studies Depression Scale (CES-D 20) among males and females with and without a history of migration. Psychiatr Prax. 2014;41:324-30.

38. Muntingh $A D$, van der Feltz-Cornelis $C M$, van Marwijk HW, Spinhoven $P$, Penninx BW, van Balkom AJ. Is the Beck Anxiety Inventory a good tool to assess the severity of anxiety? A primary care study in the Netherlands Study of Depression and Anxiety (NESDA). BMC Fam Pract. 2011;12:66.

39. Hossein Kaviani H, Mousavi AS. Psychometric properties of the Persian version of Beck Anxiety Inventory (BAI). Tehran Univ Med J. 2008;66:136-40.

40. Khesht-Masjedi MF, Omar Z, Kafi Masoleh SM. Psychometrics properties of the Persian version of Beck Anxiety Inventory in North of Iranian adolescents. Int J Educ Psychol Res. 2015;1:145-53. 
41. Malakouti SK, Pachana NA, Naji B, Kahani S, Saeedkhani M. Reliability, validity and factor structure of the CES-D in Iranian elderly. Asian J Psychiatr. 2015;18:86-90.

42. Thompson B. Exploratory and confirmatory factor analysis: understanding concepts and applications. Washington, DC: American Psychological Association; 2004

43. Beck AT, Epstein N, Brown G, Steer RA. An inventory for measuring clinical anxiety: psychometric properties. J Consult Clin Psychol. 1988;56:893-7.

44. Huang IC, Leite WL, Shearer P, Seid M, Revicki DA, Shenkman EA. Differential item functioning in quality of life measure between children with and without special health-care needs. Value Health. 2011;14:872-83.

45. Jones RN. Identification of measurement differences between English and Spanish language versions of the Mini-Mental State Examination. Detecting differential item functioning using MIMIC modeling. Med Care. 2006;44(Suppl 3):S124-33.

46. Yang FM, Tommet $\mathrm{D}$, Jones RN. Disparities in self-reported geriatric depressive symptoms due to sociodemographic differences: an extension of the bi-factor item response theory model for use in differential item functioning. J Psychiatr Res. 2009;43:1025-35.

47. Cheung GW, Rensvold RB. Evaluating goodnessof- fit indexes for testing measurement invariance. Struct Equ Model. 2002;9:233-55.

48. Chen FF. Sensitivity of goodness of fit indexes to lack of measurement invariance. Struct Equ Model. 2007;14:464-504.

49. Cook KF, Bombardier CH, Bamer AM, Choi SW, Kroenke K, Fann JR. Do somatic and cognitive symptoms of traumatic brain injury confound depression screening? Arch Phys Med Rehabil. 2011;92:818-23.

50. Hu J, Ward MM. Screening for depression in arthritis populations: an assessment of differential item functioning in three self-reported questionnaires. Qual Life Res. 2017;26:2507-17.

51. Midden AJ, Mast BT. Differential item functioning analysis of items on the Geriatric Depression Scale-15 based on the presence or absence of cognitive impairment. Aging Ment Health. 2018;22:1136-42.

52. Broekman BF, Nyunt SZ, Niti M, Jin AZ, Ko SM, Kumar R, et al. Differential item functioning of the Geriatric Depression Scale in an Asian population. J Affect Disord. 2008;108:285-90.
53. Waller NG, Compas BE, Hollon SD, Beckjord E. Measurement of depressive symptoms in women with breast cancer and women with clinical depression: a differential item functioning analysis. J Clin Psychol Med Settings. 2005;12:127-41.

54. Toledano-Toledano F, Moral de la Rubia J, Domínguez-Guedea MT, Nabors LA, Barcelata-Eguiarte BE, Rocha-Pérez E, Luna D, Leyva-López A, Rivera-Rivera L. Validity and reliability of the Beck Anxiety Inventory (BAI) for family caregivers of children with cancer. Int J Environ Res Public Health. 2020;17:7765.

55. Chapman LK, Williams SR, Mast BT, Woodruff-Borden J. A confirmatory factor analysis of the beck anxiety inventory in African American and European American young adults. J Anxiety Disord. 2009;23:387-92.

56. Osman A, Hoffman J, Barrios FX, Kopper BA, Breitenstein JL, Hahn SK. Factor structure, reliability, and validity of the Beck Anxiety Inventory in adolescent psychiatric inpatients. J Clin Psychol. 2002;58:443-56.

57. Kamen C, Arganbright J, Kienitz E, Weller M, Khaylis A, Shenkman T, et al. HIV-related stigma: implications for symptoms of anxiety and depression among Malawian women. Afr J AIDS Res. 2015;14:67-73.

58. Chandra PSKV, Ravi V, Desai A, Puttaram S. HIV related admissions in a psychiatric hospital a five year profile. Indian J Psychiatry. 1999;41:320-4.

59. Lyketsos CG, Hoover DR, Guccione M, Dew MA, Wesch JE, Bing EG, et al. Changes in depressive symptoms as AIDS develops. The Multicenter AIDS Cohort Study. Am J Psychiatry. 1996;153:1430-7.

60. Sewell MC, Goggin KJ, Rabkin JG, Ferrando SJ, McElhiney MC, Evans S. Anxiety syndromes and symptoms among men with AIDS: a longitudinal controlled study. Psychosomatics. 2000;41:294-300.

61. Woods CM. Evaluation of MIMIC-model methods for DIF testing with comparison to two-group analysis. Multivar Behav Res. 2009;44:1-27.

\section{Publisher's Note}

Springer Nature remains neutral with regard to jurisdictional claims in published maps and institutional affiliations.
Ready to submit your research? Choose BMC and benefit from:

- fast, convenient online submission

- thorough peer review by experienced researchers in your field

- rapid publication on acceptance

- support for research data, including large and complex data types

- gold Open Access which fosters wider collaboration and increased citations

- maximum visibility for your research: over $100 \mathrm{M}$ website views per year

At BMC, research is always in progress.

Learn more biomedcentral.com/submissions 